\title{
Unifying Protocols for Conducting Systematic Scoping Reviews with Application to Immersive Learning Research
}

\author{
Leonel Morgado \\ Universidade Aberta \& INESC TEC \\ Coimbra, Portugal \\ leonel.morgado@uab.pt \\ 0000-0001-5517-644X
}

\author{
Dennis Beck \\ University of Arkansas \\ Fayetteville, AR, U.S.A. \\ debeck@uark.edu \\ 0000-0003-1771-3237
}

\begin{abstract}
The progress of immersive learning research as a field requires a clear vision of its status, of the current knowledge being produced and of the open problems and gaps. Typical survey efforts however suffer from lack of systematization, providing a scattered perspective of the field. We have combined the literature on conducting systematic scoping reviews and applied it to the field, presenting the resulting protocol. It contributes a clarification on the sequence of steps and processes for delineating a gap, finding the evidence and depart from it to conduct literature reviews.
\end{abstract}

Index Terms-scoping reviews, systematic literature reviews, methodology, immersive learning research

\section{INTRODUCTION}

A comprehensive, current perspective of immersion learning research is necessary for the field to progress steadily. It can contribute to the development of common language among the research community and a common perspective on the body of literature, so that diverse areas of research more easily and consistently come together. The field of immersive learning research is currently unfocused and scattered due to a lack of common language on its foundational concepts, and consequential scattered perspective on the status of the field.

As we show in the next section, Immersion has a long history from the fields of narrative [1], psychology [2], and mass communications [3] that precedes its current, technocentric focus; Learning research has itself evolved to encompass a varied and context-rich set of areas of interest. The emerging interdisciplinary field of immersive learning research is thus the complex, multidimensional combination of these diverse fields. With such a rich background, it is a bit surprising that the field lacks a clear vision of its broad status, open problems, and gaps. But indeed, a fragmented pattern emerges when analyzing its surveys, as we show in section III. The very concept of immersion is mostly being approached via a split between a psychological state and an objective characteristic of the technical system, with little attention being given to earlier, more prevalent perspectives employed in other scientific fields. Thus, we start by clarifying that the literature already provides a unified approach to the definition of immersion, which if reaching widespread use could shed light on the current, fragmented nature of the field.

Overall, this status has resulted in a lack of systematization across the field, providing a muddled perspective of the current knowledge. Too many past efforts have leapt into systematic literature reviews without previously defining key terms and detailing methods, without identifying where the evidence is, where the reviews should be conducted and how they should focus. Systematic scoping reviews are a powerful epistemological tool to tackle this problem, since they allow researchers to "examine the extent, range, and nature of research activity, determine the value of undertaking a full systematic review, summarize and disseminate research findings, or identify gaps in the existing literature" [4].

As a contribution to change this status or immersive learning research, we synthesized scoping review approaches by Levac et al. [4] and the Joanna Briggs Institute's (JBI) [5] to develop a systematic sequence of steps and processes for the various phases of scoping reviews: delineating a gap; finding the evidence; and progressing from the evidence to conduct literature reviews. Then we instantiated the protocol for immersive learning research, to support its use by the research community in this field. To accomplish this, we established foundational definitions of immersion and immersive learning, by leveraging the literature - we integrated the definition laid out by Agrawal et al. [6] into the unified concept of immersion provided by Nilsson et al. [7]. We have also clarified the concept of immersive learning and employed it to customize the criteria stages of the unified protocol, thus readying it for application to immersive learning research.

The resulting protocol, potentially adaptable for other technical fields, can now be readily applied in order to conduct systematic literature surveys studies in immersive learning research, contributing to continuous progress towards a better understanding of the field and, ultimately, better science in immersive learning research.

\section{ClaRIFY THE SCOPE OF YOUR IMMERSIVE LEARNING RESEARCH}

\section{A. What is Immersion?}

The concept of immersion seems deceptively intuitive, and this illusory simplicity may have contributed to the cursory attention that many papers in the area give to it. As Murray's often-cited work expressed, the term originally referred to being submerged in water, summoning the metaphor of a "sensation of being surrounded by a completely other reality" [8]. This viewpoint is found in the literature of technology-infused fields across two complementary 
theoretical perspectives: that of immersion as a property of the technological systems that provide this surrounding, developed by Mel Slater and his team [9], and that of immersion as a perceptual response to that surrounding, developed from Witmer \& Singer [10]. Subsequent works by a diversity of authors contributed to both perspectives. In fields such as psychology, literary studies or educational sciences, other theoretical perspectives emerged from that metaphor, such as the roles of narratives, engagement, psychological flow and others.

Given that decades have elapsed since Immersion started to be employed as a concept in research, it is surprising that the literature in the field of Immersive Learning Research remains fragmented regarding the definition of immersion. Even literature surveys fail to provide sufficient evidence for their definition of immersion or simply choose a definition ad hoc (see next section). For example, many of the literature reviews merely cite Slater's definition [9] without any explanation or consideration of alternatives. This is unfortunate, as literature reviews that are not grounded in scholarly literature defining immersion cannot effectively contribute to the field. As a result, it may be difficult to use the results of these literature reviews as a means to provide a foundation for future research, and it certainly may explain why a majority of reviews do not cite each other.

However, two recent author teams have sought to remedy this problem. First, Nilsson, Nordahl \& Serafin [6] reviewed a variety of perspectives on immersion and created a threedimensional taxonomy conceptualizing immersion: system immersion, narrative immersion, and challenge-based immersion. Rather than provide a single definition for immersion, they instead assume it as the conjunction of these dimensions. This taxonomy, being three-dimensional, can be visualized as a cube, showing how each kind of immersion can be experienced by itself, or in tandem with one or more of the others, to varying degrees, resulting in a spatial positioning within that cube. Their approach defines system immersion as an objectively measurable property of the system and not the product of a user's reaction to that system (as per Slater [9]), and this enables them to subsume a common perspective about immersion, that stemming from Witmer \& Singer's seminal view of immersion as a perceptual response [10], which in this taxonomy becomes as a redundant overlap without additional descriptive power. Then they explain narrative immersion "....as characterized by a degree of mental absorption or intense preoccupation with the story, the diegetic space, and the characters inhabiting this space" [10, p. 114]. Finally, they define challenge-based immersion as a user's mental absorption brought about by the experience of challenges requiring mental or sensorimotor skills" [10, p. 116].

Nilsson et al.' perspective lacked a specific definition. This was later expressed by Agrawal, Simon, \& Bech [5], who also sought to resolve the disjoint views on immersion as medium vs. experience, as "a phenomenon experienced by an individual when they are in a state of deep mental involvement in which their cognitive processes (with or without sensory stimulation) cause a shift in their attentional state such that one may experience disassociation from the awareness of the physical world" (p. 5). This definition is consistent with the Nilsson et al.'s perspective, providing a clarifying summary of the concept. Thus, for this paper, we use Agrawal's definition and adopt Nilsson's taxonomy as an explanatory metaphor.

Now that we have defined immersion, we turn to the combination of the immersion with learning.

\section{B. What is Immersive Learning?}

In Learning Sciences, traditionally the main areas of research were focused on how experts differ from novices, the transfer of learning to different contexts and situations, how children learn at different ages, and neuroscience research on the mind and brain. Conversely, teaching-related research tends to center on the design of learning environments, effective teaching examples in different subject areas, teacher learning, and the use of technology to support learning [11]. More recently, holistic approaches have emerged, advocating a perspective on learning as a phenomenon framed by a diversity of contexts (cultural, social, cognitive, and biological) [12], Thus current learning and teaching research now seeks to understand not only learning aspects, processes, and content, but contributions from these wider contexts: motivation, applications of research to school practice, the use of digital technologies for learning, lifelong learning, and more [12]. For instance, the US National Academies of Sciences, Engineering, and Medicine included as part of a research agenda the need to research the influence of learning environments, including aspects such as "how the culture of the learning environment influences learners' sense of belonging, adaptability, agency, and learning outcomes (...) identify the types of learning associated with particular learning tasks and environments and (...) track the predicted consequences for learning, motivation, emotion, and social interaction (...) explain how methods of instruction prime a positive connection between current learning efforts and desired future outcomes" [12].

"Immersive learning" thus emerges as part of this novel research perspective on the relevance of the context for learning and teaching, with immersion providing a theoretical lens to analyze, interpret, and shape that context. For example, researchers interested in learning differences of experts vs. novices may analyze these differences under the lens of immersion, by considering system, narrative, and challenge dimensions. Conversely, other researchers may interpret learning transfer by exploration of its relationship with immersion, via narrative elements (e.g., diegetic space) challenge dynamics, and system context. Still others may be interested in promoting teacher's education, by shaping the system properties, challenge structure, and narrative elements towards different immersion spaces.

\section{Clarify your Definitions and Scope}

As shown by the subtleties of the concepts provided in the two previous subsections, conducting a scoping review in the field of immersive learning research without prior clarification of definitions can be risky. By simply considering "immersion" to be a technological phenomenon, a scoping review will ignore whole fields of knowledge that may in hindsight be deemed relevant. Conversely, by not delimiting the scope, you begin a data collection effort which is lengthy and wasteful of time and effort, because you do not make important connections between the literature available and the actual objectives for the scoping review.

Thus, immersive learning researchers beginning a scoping review should start by reflecting on the definition and 
dimensions of immersion as well as the wider perspective of learning and teaching research as occurring within an encompassing context. They should then use these delimiters to frame goals, establish clear definitions for concepts driving the scoping review, and ultimately establishing the proper scope.

For example, we are currently conducting a scoping literature review on actual accounts of immersive environments being employed for learning as reported by researchers. Using the definition of immersion above, we realized our goals were aligned with the use of digital technologies, and thus excluded from the scope works about immersion emerging solely from oral storytelling, physical sports, paper books, or mechanical airplane simulators. Subsequently, by considering the narrative and challenge dimensions of immersion, we recognized that digital technologies such as word processors or PDF files would qualify, even though they were not aligned with our goals. This helped us to clarify that our concern was with technology designed with the intent to elicit immersion. Thus, considering the definitions carefully allowed us to much better refine the scope of our work beforehand.

Similarly, by considering the wider perspective on learning research, we avoid accidentally excluding areas that would be relevant for our goal. The analysis of the panorama and diversity of interests in learning research would eventually lead us to identifying the overall area of interest as the application of research to practice, and within that the need to consider as distinct aspects the uses, practices, and strategies with immersive learning environments.

Likewise, researchers envisaging a scoping review in this field should consider the definitions and scope involved by framing their interests over this combined perspective of immersion and learning research.

\section{CURRENT STATUS OF IMMERSIVE LEARNING RESEARCH SURVEY EFFORTS}

We collected a brief methodological sample of literature surveys on immersive learning research by harvesting from Google Scholar papers with two search strings for the date span 2000-2020:

1. Title with: (survey OR review) AND immersive AND learning

2. Title with: (survey OR review) AND learning + Publication name with: immersive OR virtual

After correcting citation data on the results and consolidating duplicates, we got $n=37$ papers. We removed book reviews, books (not chapters), posters, and project reports but not technical reports $(n=32)$, a foreign-language paper which we were unable to read $(n=31)$ and those inaccessible behind paywalls not included in our institutional subscriptions $(n=27)$. We then excluded those not related to immersive learning, or not actually being literature reviews, by reading their titles and abstracts and, when in doubt, the contents $(n=12)$. The resulting corpus is presented in Table I.

By analyzing the concepts of "immersion" employed by these surveys, as shown in Table II, a third (4/12) of the sample neglects to clarify the term, simply employing it. More than half (7/12) address the technological fidelity aspect of the definition. Two address engagement immersion, one addresses interaction immersion, and one addresses narrative immersion. Only a fourth (3/12) of the papers address more than one aspect of immersion.

The theoretical grounding on which the surveys build from these perspectives is thin. A third (4/12) of the papers neglect to provide a reference for the concept of immersion. However, since almost all the remaining papers provided isolated references for their concepts of immersion, we analyzed those to establish their original grounding of the term - that is, we checked the actual theoretical basis for their employed concepts of immersion, either directly in the referenced papers or indirectly in their snowballed references. Fifty-eight percent of the papers (7/12) either neglected to ground the concept of immersion or pointed to references which did not do it themselves. Of the remaining survey papers, three provided a reference which was either directly or indirectly grounded in the concept of technological fidelity immersion, and one paper each provided references directly or indirectly grounded in interaction immersion, engagement immersion or narrative immersion.

TABLE I. CORPUS OF SURVEYS ON IMMERSIVE LEARNING RESEARCH

\begin{tabular}{|c|c|c|}
\hline Authors & Title & Year \\
\hline Ali et al. & $\begin{array}{l}\text { A survey on Immersive learning approach towards } \\
\text { current education system }\end{array}$ & 2019 \\
\hline $\begin{array}{l}\text { Checa \& } \\
\text { Bustillo }\end{array}$ & $\begin{array}{l}\text { A review of immersive virtual reality serious games } \\
\text { to enhance learning and training }\end{array}$ & 2019 \\
\hline Hillstrom & $\begin{array}{l}\text { Virtual Place-Based Learning in Interdisciplinary } \\
\text { Contexts: A Psychological Perspective and a Meta- } \\
\text { analytic Review }\end{array}$ & 2019 \\
\hline $\begin{array}{l}\text { Pellas et } \\
\text { al. }\end{array}$ & $\begin{array}{l}\text { Augmenting the learning experience in primary and } \\
\text { secondary school education: a systematic review of } \\
\text { recent trends in augmented reality game-based } \\
\text { learning }\end{array}$ & 2019 \\
\hline $\begin{array}{l}\text { Ravyse et } \\
\text { al. }\end{array}$ & $\begin{array}{l}\text { Success factors for serious games to enhance } \\
\text { learning: a systematic review }\end{array}$ & 2017 \\
\hline $\begin{array}{l}\text { Kawaka } \\
\text { mi et al. }\end{array}$ & $\begin{array}{l}\text { Three-Dimensional Virtual Environments That } \\
\text { Support Hospitalized Children's Learning: A } \\
\text { Systematic Review }\end{array}$ & 2015 \\
\hline $\begin{array}{l}\text { Kleinert } \\
\text { et al. }\end{array}$ & $\begin{array}{l}\text { 3D immersive patient simulators and their impact on } \\
\text { learning success: a thematic review }\end{array}$ & 2015 \\
\hline $\begin{array}{l}\text { Nussli \& } \\
\text { Oh }\end{array}$ & $\begin{array}{l}\text { The components of effective teacher training in the } \\
\text { use of three-dimensional immersive virtual worlds } \\
\text { for learning and instruction purposes: A literature } \\
\text { review }\end{array}$ & 2014 \\
\hline $\begin{array}{l}\text { Soliman } \\
\& \text { Guetl }\end{array}$ & $\begin{array}{l}\text { Intelligent pedagogical agents in immersive virtual } \\
\text { learning environments: A review }\end{array}$ & 2010 \\
\hline Hansen & $\begin{array}{l}\text { Versatile, immersive, creative and dynamic virtual } \\
\text { 3-D healthcare learning environments: a review of } \\
\text { the literature }\end{array}$ & 2008 \\
\hline de Freitas & $\begin{array}{l}\text { Learning in immersive worlds: A review of game- } \\
\text { based learning }\end{array}$ & 2006 \\
\hline $\begin{array}{l}\text { Tolsby et } \\
\text { al. }\end{array}$ & $\begin{array}{l}\text { A Survey of Technologies Supporting Virtual } \\
\text { Project Based Learning }\end{array}$ & 2002 \\
\hline
\end{tabular}


Also, only one survey in this corpus references an earlier survey from the same corpus. It was expected that a survey would reference earlier survey efforts from its field, but this expectation was not confirmed.

Regarding the use of scoping for establishing the range and location of evidence for the literature reviews, as Table III details, none of the papers in the corpus employed systematic scoping. A third conducted a scoping stage, planning the literature review with several dimensions of scoping, but two-thirds (9/12) either did minimal scoping (keyword selection or similar) or provided no methodological information on how they conducted their review.

TABLE II. IMMERSION PERSPECTIVES AND THEORIES USED IN THE SURVEYS

\begin{tabular}{|c|c|c|c|}
\hline $\begin{array}{c}\text { Immersion } \\
\text { perspective }\end{array}$ & $\begin{array}{c}\text { No. } \\
\text { papers }^{a}\end{array}$ & Main ref. on immersion $^{b}$ & $\begin{array}{c}\text { No. } \\
\text { papers }^{a}\end{array}$ \\
\hline $\begin{array}{c}\text { Technological } \\
\text { fidelity }\end{array}$ & 7 & $\begin{array}{c}\text { Slater (2003) or Slater \& } \\
\text { Wilbur (1997) or Azuma } \\
\text { (1997) }\end{array}$ & 3 \\
\hline Unspecific & 4 & None & 6 \\
\hline Engagement & 2 & $\begin{array}{c}\text { Csikszentmihalyi (1992) } \\
\text { and/or Kolb (1984) }\end{array}$ & 1 \\
\hline Interaction & 1 & Barab (2007) & 1 \\
\hline Narrative & 1 & Whitton (2011) & 1 \\
\hline
\end{tabular}

a. Sum of immersion perspective is not $n=12$ because three papers employ two perspectives.

TABLE III

USAGE OF SCOPING IN THE REVIEW METHODS

\begin{tabular}{|l|c|}
\hline \multicolumn{1}{|c|}{ Type of scoping } & No. papers \\
\hline Minimal prior scoping & 5 \\
\hline No methodological information & \\
\hline Prior scoping, not systematic & 4 \\
\hline Systematic scoping & 3 \\
\hline
\end{tabular}

IV. COMPARISON OF THE TWO MAIN METHODS FOR CONDUCTING SCOPING REVIEWS

In the wake of Arksey \& O'Malley's seminal 2005 methods paper on scoping reviews [13], several improvements have been proposed in the literature. Current scoping reviews usually follow either Levac et al.'s proposal [4] or the Joanna Briggs Institute's (JBI) proposal [5]. These are summarized side-by-side in Table IV.

For clarity, we have homogenized numbering. For instance, Levac at el. use \#n for a stage number and then $n \mathrm{a}$, $n \mathrm{~b}$ and $n \mathrm{c}$ for its substages. JBI doesn't use any numbering, only different levels of headings. We use for both the nomenclature $n ., n .1, n .2$, etc. We also aligned the stages and substages as much as possible. For instance, Levac et al.'s stage one mostly resembles JBI's second stage, so these appear in the same row of Table IV. Also, JBI's third substage of their second stage (i.e., 2.3) mostly comprises Levac et al.'s substages 1.1 and 1.2, and this is visually displayed in the table. Finally, we have sometimes split a longer process into substages, for the benefit of comparison. For instance, the description of JBI's fourth stage is here presented as substages 4.1 through 4.4 .

TABLE IV. $\quad$ LEVAC ET AL. VIS-À-VIS JOANNA BRIGGS INSTITUTE.

\begin{tabular}{|c|c|}
\hline Levac et al. [4] & Joanna Briggs Institute [5] \\
\hline Stages \& substages & Stages \& substages \\
\hline [addressed below in stage 2.2] & 1. Identify at least two reviewers \\
\hline 1. Identifying the research question & $\begin{array}{l}\text { 2. Develop a priori scoping review } \\
\text { protocol }\end{array}$ \\
\hline [not mentioned in this protocol] & 2.1 Define Title \\
\hline [not mentioned in this protocol] & 2.2 Define background \\
\hline $\begin{array}{l}1.1 \text { Clearly articulate the } \\
\text { research question that will guide } \\
\text { the scope of inquiry. }\end{array}$ & \multirow[t]{2}{*}{$\begin{array}{l}\text { 2.3 Define review } \\
\text { question(s)/objective(s) }\end{array}$} \\
\hline $\begin{array}{l}1.2 \text { Mutually consider the } \\
\text { purpose of the scoping study } \\
\text { with the research question. } \\
\text { Envision the intended outcome }\end{array}$ & \\
\hline $\begin{array}{l}1.3 \text { Consider rationale for } \\
\text { conducting the scoping study }\end{array}$ & $\begin{array}{l}\text { 2.4 Define inclusion criteria: } \\
\text { rationale or justification } \\
\text { following background }\end{array}$ \\
\hline \multicolumn{2}{|l|}{ 2. Identifying relevant studies } \\
\hline $\begin{array}{l}2.1 \text { Decision-making about the } \\
\text { scope checking question and } \\
\text { purpose }\end{array}$ & [addressed in stages 2.5-2.7] \\
\hline [addressed above in stage 2.1] & 2.5 Define types of participants \\
\hline 2.2 Assemble a suitable team & [already addressed in stage 1] \\
\hline \multirow[t]{4}{*}{$\begin{array}{l}2.3 \text { Justify decisions for when } \\
\text { limiting scope is unavoidable }\end{array}$} & $\begin{array}{l}2.6 \text { Define concept (scope and } \\
\text { breadth) }\end{array}$ \\
\hline & $\begin{array}{l}\text { 2.7 Define context: geography, } \\
\text { location, culture, demographics, } \\
\text { discipline, etc. }\end{array}$ \\
\hline & 3. Searching \\
\hline & $\begin{array}{l}\text { 3.1 Define languages and } \\
\text { publication date limitations }\end{array}$ \\
\hline \multicolumn{2}{|l|}{ 3. Study selection } \\
\hline \multirow[t]{3}{*}{$\begin{array}{l}\text { 3.1 Iterative process: search the } \\
\text { literature, refine the strategy, } \\
\text { review articles for inclusion }\end{array}$} & $\begin{array}{l}\text { 3.2 Initial limited selection of } \\
\text { relevant databases, followed by } \\
\text { an analysis of text words in title } \\
\text { and abstract, and index terms }\end{array}$ \\
\hline & $\begin{array}{l}\text { 3.3 Second search using all } \\
\text { identified keywords and index } \\
\text { terms across all included } \\
\text { databases }\end{array}$ \\
\hline & $\begin{array}{l}\text { 3.4 Searching reference list of all } \\
\text { identified reports and articles }\end{array}$ \\
\hline
\end{tabular}




\begin{tabular}{|c|c|}
\hline & for additional studies \\
\hline $\begin{array}{l}3.2 \text { Start with team meeting to } \\
\text { discuss criteria for study } \\
\text { inclusion and exclusion. }\end{array}$ & [already addressed in stage 2.4] \\
\hline $\begin{array}{l}3.3 \text { Reviewers meet at the } \\
\text { beginning, midpoint and final } \\
\text { stages of the abstract review } \\
\text { process to discuss challenges } \\
\text { and uncertainties related to study } \\
\text { selection and to go back and } \\
\text { refine the search strategy if } \\
\text { needed. }\end{array}$ & [already addressed in stage 3.2] \\
\hline $\begin{array}{l}\text { 3.4 Two researchers } \\
\text { independently review full } \\
\text { articles for inclusion }\end{array}$ & [not mentioned in this protocol] \\
\hline $\begin{array}{l}3.5 \text { When disagreements on } \\
\text { study inclusion occur, a third } \\
\text { reviewer can determine final } \\
\text { inclusion. }\end{array}$ & [not mentioned in this protocol] \\
\hline 4. Charting the data & $\begin{array}{l}\text { 4. Extracting and charting the } \\
\text { results }\end{array}$ \\
\hline \multirow[t]{2}{*}{$\begin{array}{l}\text { 4.1 Research team collectively } \\
\text { develop data-charting form and } \\
\text { determine variables to extract }\end{array}$} & $\begin{array}{l}\text { 4.1 Narrative description of the } \\
\text { search decision process } \\
\text { accompanied by the search } \\
\text { decision flowchart }\end{array}$ \\
\hline & $\begin{array}{l}\text { 4.2 Draft charting table or form } \\
\text { should be developed as part of } \\
\text { the protocol to record } \\
\text { characteristics and data }\end{array}$ \\
\hline $\begin{array}{l}4.2 \text { Iterative charting, } \\
\text { continuous extraction of data } \\
\text { and updating form }\end{array}$ & \multirow{3}{*}{$\begin{array}{l}\text { 4.3 Reviewers trial the } \\
\text { extraction form on two or three } \\
\text { studies to ensure all relevant } \\
\text { results are extracted. Then do } \\
\text { refinement of the charting forms }\end{array}$} \\
\hline $\begin{array}{l}\text { 4.3 Two researchers } \\
\text { independently extract into the } \\
\text { form data from the first five to } \\
\text { ten included studies and meet to } \\
\text { determine whether data } \\
\text { extraction is consistent }\end{array}$ & \\
\hline $\begin{array}{l}\text { 4.4 Process-oriented data may } \\
\text { require extra planning for } \\
\text { analysis. A qualitative content } \\
\text { analysis approach is suggested. }\end{array}$ & \\
\hline $\begin{array}{l}\text { 5. Collating, summarizing, and } \\
\text { reporting the results }\end{array}$ & $\begin{array}{l}\text { 4.4 Detail a proposed plan for } \\
\text { presenting the results }\end{array}$ \\
\hline $\begin{array}{l}\text { 5.1 Analysis (including } \\
\text { descriptive numerical summary } \\
\text { analysis and qualitative thematic } \\
\text { analysis) }\end{array}$ & $\begin{array}{l}\text { [not explicitly said when it is done, } \\
\text { instead JBI's protocol focuses on } \\
\text { recommendations for this action] }\end{array}$ \\
\hline $\begin{array}{l}5.2 \text { Reporting the results and } \\
\text { producing the outcome }\end{array}$ & $\begin{array}{l}4.5 \text { Logical and descriptive } \\
\text { summary of the results }\end{array}$ \\
\hline [not mentioned in this protocol] & $\begin{array}{l}\text { 4.6 Extracted results classified } \\
\text { under main conceptual } \\
\text { categories }\end{array}$ \\
\hline \multirow{2}{*}{$\begin{array}{l}\text { 5.3 Consider the meaning of the } \\
\text { findings as they relate to the } \\
\text { overall study purpose; discuss }\end{array}$} & 5. Discussion \\
\hline & $\begin{array}{l}5.1 \text { In-depth discussion of the } \\
\text { results of the review, as well as }\end{array}$ \\
\hline
\end{tabular}

\begin{tabular}{|c|c|}
\hline \multirow[t]{3}{*}{$\begin{array}{l}\text { implications for future research, } \\
\text { practice and policy }\end{array}$} & $\begin{array}{l}\text { any limitations, in the context of } \\
\text { the current literature, practice, } \\
\text { and policy }\end{array}$ \\
\hline & $\begin{array}{l}\text { 6. Conclusions and implications for } \\
\text { research and practice }\end{array}$ \\
\hline & $\begin{array}{l}6.1 \text { match the review } \\
\text { objective/question and include } \\
\text { an overall conclusion based } \\
\text { upon the results of the scoping } \\
\text { review }\end{array}$ \\
\hline 6. Consultation (optional) & [not mentioned in this protocol] \\
\hline $\begin{array}{l}\text { 6.1 Consultation should be an } \\
\text { essential component }\end{array}$ & [not mentioned in this protocol] \\
\hline $\begin{array}{l}6.2 \text { Clearly establish a purpose } \\
\text { for the consultation }\end{array}$ & [not mentioned in this protocol] \\
\hline $\begin{array}{l}\text { 6.3 Preliminary findings can be } \\
\text { used as a foundation to inform } \\
\text { the consultation }\end{array}$ & [not mentioned in this protocol] \\
\hline $\begin{array}{l}6.4 \text { Clearly articulate the type of } \\
\text { stakeholders to consult and how } \\
\text { data will be collected, analyzed, } \\
\text { reported and integrated within } \\
\text { the overall study outcome }\end{array}$ & [not mentioned in this protocol] \\
\hline $\begin{array}{l}6.5 \text { Incorporate opportunities for } \\
\text { knowledge transfer and } \\
\text { exchange with stakeholders in } \\
\text { the field. }\end{array}$ & [not mentioned in this protocol] \\
\hline
\end{tabular}

\section{A UNIFIED METHOD FOR SYSTEMATIC SCOPING REVIEWS IN IMMERSIVE LEARNING RESEARCH}

\section{A. The Unified and Refined Protocol}

Both proposals summarized in Table IV provide articulate methods for conducting systematic scoping reviews. JBI's is more detailed, particularly in preparation stages, but on the search and analysis process Levac et al. provide details which are absent from JBI's. For instance, compare JBI's 4.3 with its mirror in Levac et al., 4.2, 4.3 and 4.4. We have combined the details for clarity. However, we have opted not to include the optional stage (consultation) of the Levac et al. process, viewing it as a subsequent and independent study that may stem from the scoping review, rather than part of the review itself.

The interdisciplinary nature of immersive learning research leads to some shortcomings in both protocols, such as situations where prior actions are impacted by later decisions. For instance, JBI's proposes 2.6 (define concept to guide the scope and breadth) after having defined inclusion criteria and types of participants. However, "participants" in immersive learning studies may be not just humans, but also organizations, government bodies, information systems and technology, or yet other foci of study. And those foci can be approached in significantly different ways, such as outcome analysis vs. practice reports. Thus, we recommend defining the concept before establishing the criteria and split these into three clear categories: concept-based, participant-based, and context-based criteria.

Thus, the combined protocol presented in Table $\mathrm{V}$ goes beyond merging the two prior ones: it builds on them considering the interdisciplinary and transdisciplinary nature of immersive learning research. 


\section{B. The Protocol as Part of a Larger Process}

The protocol presented in the previous section is part of a larger process for establishing the current knowledge in immersive learning research: 1) Defining the scope; 2) Locating the evidence; 3) Locating the knowledge (doing several systematic reviews based on the located evidence). The scoping itself may be seen as a sequential process, but as Table V details it includes two iteration moments. Thus, Fig. 1 is provided to highlight this overall and iterative workflow.

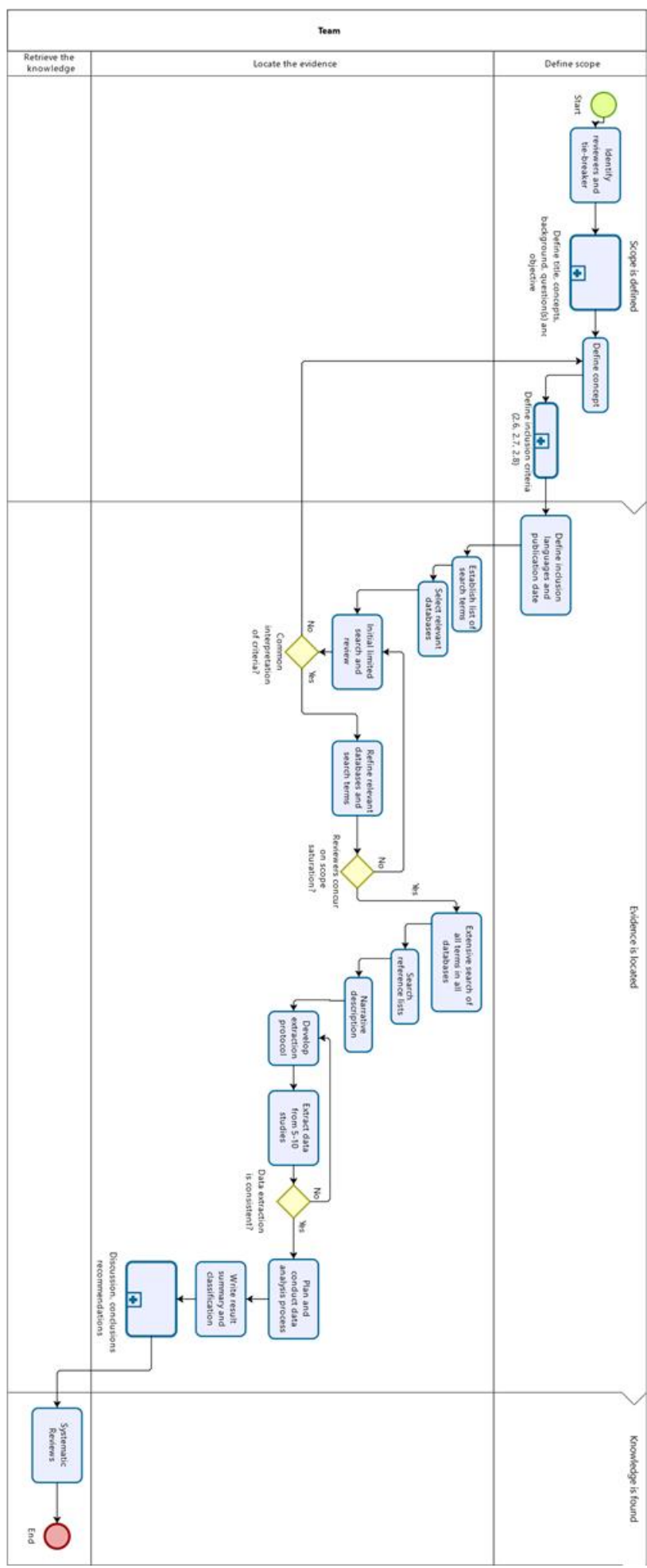

Fig. 1. Overall process from scoping review to literature reviews.
TABLE V.

UNIFIED PROTOCOL FOR SYSTEMATIC SCOPING REVIEWS IN IMMERSIVE LEARNING RESEARCH.

\begin{tabular}{|c|c|c|}
\hline Stages & Description with comments & $\begin{array}{l}\text { Adapted } \\
\text { from }^{a}\end{array}$ \\
\hline 1 & $\begin{array}{l}\text { Identify at least a pair of main reviewers and a } \\
\text { tiebreaker } \\
\text { Combine fields of expertise for interdisciplinary } \\
\text { and transdisciplinary approaches to immersive } \\
\text { learning. }\end{array}$ & [5] \\
\hline 2 & Develop first version of the scoping review protocol & [5] \\
\hline 2.1 & $\begin{array}{l}\text { Define title } \\
\quad \text { Reflecting concept, context, perspective }\end{array}$ & [5] \\
\hline 2.2 & $\begin{array}{l}\text { Define foundational concepts } \\
\text { Definitions of "immersion", "learning", and } \\
\text { concept-related aspects, such as immersive } \\
\text { environment, technology, learning context, } \\
\text { etc. }\end{array}$ & [5] \\
\hline 2.3 & $\begin{array}{l}\text { Define theoretical background } \\
\text { Present the current gap and sustain its } \\
\text { epistemological relevance for immersive } \\
\text { learning research, explaining the purpose and } \\
\text { implications. } \\
\text { Demonstrate the gap by performing a survey } \\
\text { of surveys in the field for the proposed } \\
\text { gap/purpose. }\end{array}$ & [5] \\
\hline 2.4 & $\begin{array}{l}\text { Define review question(s) and objective } \\
\text { Mutually consider the purpose of the scoping } \\
\text { study with the research question. Envision the } \\
\text { intended outcome (e.g. framework, list of } \\
\text { recommendations). }\end{array}$ & $\begin{array}{l}{[5]} \\
{[4]}\end{array}$ \\
\hline 2.5 & $\begin{array}{l}\text { Define concept } \\
\text { Clearly detailed to guide the review's scope } \\
\text { and breadth. }\end{array}$ & [5] \\
\hline 2.6 & $\begin{array}{l}\text { Define concept-based inclusion criteria } \\
\text { Rationale for each must stem from the } \\
\text { foundational concepts (2.2), and purpose and } \\
\text { theoretical background (2.3). Criteria operate } \\
\text { of concrete instances of those concepts and } \\
\text { background. For instance, criteria delimiting } \\
\text { the approach to immersion, the approach to } \\
\text { learning, etc. }\end{array}$ & $\begin{array}{l}{[5]} \\
{[4]}\end{array}$ \\
\hline 2.7 & $\begin{array}{l}\text { Define participant-based inclusion criteria } \\
\text { Determine if the participants under analysis } \\
\text { should be humans, technology, organizations, } \\
\text { government bodies, media sources, academic } \\
\text { papers, etc. - or some combination of these. } \\
\text { Justify based on the purpose and background, } \\
\text { and on the foundational concepts. }\end{array}$ & [5] \\
\hline 2.8 & $\begin{array}{l}\text { Define context-based inclusion criteria } \\
\text { Delimit the scope regarding the context of } \\
\text { relevant studies: geography, location, culture, } \\
\text { demographics, discipline, etc. Justify based on } \\
\text { the purpose and background, and on the } \\
\text { foundational concepts. Acknowledge } \\
\text { limitations. }\end{array}$ & $\begin{array}{l}{[5]} \\
{[4]}\end{array}$ \\
\hline 3 & Iterative searching & {$[4,5]$} \\
\hline 3.1 & $\begin{array}{l}\text { Define inclusion languages and publication date } \\
\text { Justify based not only on team capabilities, } \\
\text { but also on significant developments in } \\
\text { immersive learning research related to the }\end{array}$ & [5] \\
\hline
\end{tabular}




\begin{tabular}{|c|c|c|}
\hline & $\begin{array}{l}\text { purpose. For instance, emergence of specific } \\
\text { technology, seminal theoretical papers, or } \\
\text { others - sustain the relevance of this decision } \\
\text { and eventual limitations, based on the } \\
\text { foundational concepts. }\end{array}$ & \\
\hline 3.2 & $\begin{array}{l}\text { Establish list of search terms for initial search } \\
\text { Using the questions and objective (2.4), } \\
\text { leverage the foundational concepts and } \\
\text { theoretical background to create a list of terms } \\
\text { to be used in the initial search. }\end{array}$ & \\
\hline 3.3 & $\begin{array}{l}\text { Select relevant databases for the initial search } \\
\text { Consider the main disciplines of study } \\
\text { associated with your questions, objective, and } \\
\text { concept, to select and justify where the first } \\
\text { search will be conducted. }\end{array}$ & [5] \\
\hline 3.4 & $\begin{array}{l}\text { Initial limited search of selected databases by } \\
\text { terms in title and abstract and review for inclusion } \\
\text { At least two reviewers (from the major } \\
\text { disciplines of focus for the survey) conduct } \\
\text { this independently and meet early in this stage } \\
\text { and then more time, to discuss challenges and } \\
\text { uncertainties related to study selection, if } \\
\text { necessary going back to refine the concept and } \\
\text { search strategy if needed. This stage is } \\
\text { complete when the reviewers establish } \\
\text { common interpretation of criteria. }\end{array}$ & [5] \\
\hline 3.5 & $\begin{array}{l}\text { Refine relevant databases and search terms } \\
\text { Check for new terms in titles, abstracts, and } \\
\text { keywords of retrieved papers and their lists of } \\
\text { references. } \\
\text { Refine the databases based on the publication } \\
\text { outlets of early results and their lists of } \\
\text { references. } \\
\text { Map authors' citation relationships, } \\
\text { identifying clusters, and checking clusters for } \\
\text { differences in terminology. } \\
\text { Return to } 3.4 \text { as necessary until reviewers } \\
\text { concur on scope saturation. }\end{array}$ & \\
\hline 3.6 & $\begin{array}{l}\text { Extensive search using all identified terms across } \\
\text { all included databases } \\
\text { Two researchers independently review all full } \\
\text { articles for inclusion. Disagreements are } \\
\text { submitted to a tie-breaker researcher. }\end{array}$ & [5] \\
\hline 3.7 & $\begin{array}{l}\text { Searching reference list of all identified articles for } \\
\text { additional studies } \\
\text { Two researchers independently review all full } \\
\text { additional studies for inclusion. } \\
\text { Disagreements are submitted to a tie-breaker } \\
\text { researcher. }\end{array}$ & [5] \\
\hline 3.8 & $\begin{array}{l}\text { Narrative description of the search decision } \\
\text { process accompanied by the search decision } \\
\text { flowchart. }\end{array}$ & [5] \\
\hline 4 & Extracting and analyzing the results & {$[4,5]$} \\
\hline 4.1 & $\begin{array}{l}\text { Develop data extraction protocol with table and/or } \\
\text { forms }\end{array}$ & {$[5]$} \\
\hline 4.2 & $\begin{array}{l}\text { Iterative data extraction and extraction protocol } \\
\text { refinement } \\
\text { Two researchers independently extract into the } \\
\text { table/form data from the first five to ten } \\
\text { included studies and meet to determine } \\
\text { whether data extraction is consistent. Process- }\end{array}$ & {$[4,5]$} \\
\hline
\end{tabular}

\begin{tabular}{|c|l|c|}
\hline & $\begin{array}{c}\text { oriented data may require qualitative content } \\
\text { analysis (e.g., thematic analysis) for refining } \\
\text { table/form. }\end{array}$ & \\
\hline 4.3 & Plan the data analysis process & {$[5]$} \\
\hline 4.4 & $\begin{array}{l}\text { Conduct the previously planned analysis } \\
\text { (including descriptive numerical summary analysis } \\
\text { and qualitative thematic analysis). }\end{array}$ & {$[4]$} \\
\hline 4.5 & $\begin{array}{l}\text { Write a logical and descriptive summary of the } \\
\text { results }\end{array}$ & {$[5]$} \\
\hline 4.6 & $\begin{array}{l}\text { Classify the extraction results under main } \\
\text { conceptual categories. }\end{array}$ & {$[5]$} \\
\hline 5 & $\begin{array}{l}\text { Discussion } \\
\text { Consider the meaning of the findings as they relate } \\
\text { to the overall study purpose; discuss implications } \\
\text { for future research, practice and policy. }\end{array}$ & {$[4]$} \\
\hline 6 & Conclusions and implications for research and practice & {$[5]$} \\
\hline 6.1 & $\begin{array}{l}\text { Match the review objective/questions and include } \\
\text { an overall conclusion based upon the results of the } \\
\text { scoping review. }\end{array}$ & {$[5]$} \\
\hline 6.2 & $\begin{array}{l}\text { Provide clear, specific recommendations for future } \\
\text { research based on gaps in knowledge identified } \\
\text { from the results of the review. These should } \\
\text { include suggestions for future systematic reviews } \\
\text { that may be of primary interest in view of the } \\
\text { outcome of the scoping review. }\end{array}$ & {$[5]$} \\
\hline
\end{tabular}

[4], [5] Levac et al. or JBI, respectively.

\section{Final Thoughts}

This paper synthesized the two main protocols used for systematic scoping reviews into a single, more robust, protocol, potentially applicable to any technical field. Then we customized it for immersive learning researchers, defining the field's foundational concepts of "immersion" and "immersive learning" based on recent literature in the field. Next, we clarified the application of several of the phases and steps, by providing examples or guidelines of aspects that immersive learning researchers should consider, based on the literature.

The resulting protocol should provide a useful tool for researchers in immersive learning as they conduct their own scoping reviews, following the sequence of steps and processes for delineating a gap, finding the evidence and reporting the results. The scoping can then be used to prepare systematic literature survey studies in the field, contributing to continuous progress towards a better understanding of the field and, ultimately, better science in immersive learning research. This should result in a unified perspective on the research literature in the field which uses similar definitions and methods to show connections between and building upon past research while maximizing the potential for the impact between research and practice.

\section{ACKNOWLEDGMENTS}

This work is co-financed by the ERDF - European Regional Development Fund through the Operational Programme for Competitiveness and Internationalization COMPETE 2020 and the Lisboa 2020 under the PORTUGAL 2020 Partnership Agreement, and through the Portuguese National Innovation Agency (ANI) as a part of project CHIC POCI-01-0247-FEDER-024498. And also by national funds 
through the FCT - Fundação para a Ciência e a Tecnologia, I.P., as part of project UID/CED/00194/2019, SCReLProg.

\section{REFERENCES}

[1] R. Gerrig, "Experiencing Narrative Worlds." Routledge, 2018

[2] F. Vincelli, "From Imagination to Virtual Reality: The Future of Clinical Psychology", Cyberpsychol. Behav. 2, 241-248, 1999, https://doi.org/10.1089/109493199316366.

[3] J. Williams, E. Christie, "The social psychology of telecommunications", Wiley, London; New York, 1976.

[4] D. Levac, H. Colquhoun, K.K. O’Brien, "Scoping studies: advancing the methodology", Implement. Sci. 5, 69 2010, https://doi.org/10.1186/1748-5908-5-69.

[5] M.D. J. Peters, C.M. Godfrey, H. Khalil, P. McInerney, D. Parker, C.B Soares, "Guidance for conducting systematic scoping reviews", Int. J. Evid. Based Healthc, 13, 141-146 2015, https://doi.org/10.1097/XEB.0000000000000050.

[6] N.C. Nilsson, R. Nordahl, S. Serafin, "Immersion Revisited: A review of existing definitions of immersion and their relation to different theories of presence", Hum. Technol. 12, 108-134, 2016, https://doi.org/10.17011/ht/urn.201611174652.

[7] S. Agrawal, A. Simon, S. Bech, "Defining Immersion: Literature Review and Implications for Research on Immersive Audiovisual Experiences", N. Y. 14, 2019.

[8] J.H. Murray, "Hamlet on the holodeck: the future of narrative in cyberspace", The MIT Press, Cambridge, Massachusetts London,
England, 2017.

[9] M. Slater, "Place illusion and plausibility can lead to realistic behaviour in immersive virtual environments", Philos. Trans. R. Soc. B Biol. Sci. 364, 3549-3557, 2009, https://doi.org/10.1098/rstb.2009.0138.

[10] B.G. Witmer, M.J. Singer, "Measuring Presence in Virtual Environments: A Presence Questionnaire", Presence Teleoperators Virtual Environ. 7, pp. 225-240, 1998, https://doi.org/10.1162/105474698565686.

[11] J. Bransford, National Research Council (U.S.), National Research Council (U.S.) eds, "How people learn: brain, mind, experience, and school", National Academy Press, Washington, D.C, 2000.

[12] Committee on How People Learn II: The Science and Practice of Learning, Board on Behavioral, Cognitive, and Sensory Sciences, Board on Science Education, Division of Behavioral and Social Sciences and Education, National Academies of Sciences, Engineering, and Medicine: How People Learn II: Learners, Contexts, and Cultures. National Academies Press, Washington, D.C, 2018.

[13] H. Arksey, L. O'Malley, "Scoping studies: towards a methodological framework", Int. J. Soc. Res. Methodol. 8, 19-32 2005. https://doi.org/10.1080/1364557032000119616.

[14] A.C. Tricco, E. Lillie, W. Zarin, K. O’Brien, H. Colquhoun, M. Kastner, D. Levac, C. Ng, J.P. Sharpe, K. Wilson, M. Kenny, R. Warren, C. Wilson, H.T Stelfox, S.E. Straus, "A scoping review on the conduct and reporting of scoping reviews", BMC Med. Res. Methodol. 16, 15, 2016, https://doi.org/10.1186/s12874-016-0116-4. 